\title{
NORMAS EDITORIALES
}

\section{Tipos de artículos que podrán ser presentados para su publicación en Lex}

Los artículos presentados para su evaluación y eventual publicación pueden ubicarse dentro de la siguiente tipología:

a. Artículos de investigación científica. Exponen de manera detallada los resultados de una investigación. Su estructura está definida por la presencia de cinco partes esenciales: introducción, metodología, resultados, discusión y conclusiones.

b. Artículos de reflexión. Ensayos académicos en torno de un tema específico y que se desarrollan desde un punto de vista que puede ser crítico o interpretativo, apelando a la consulta de diversas fuentes.

c. Artículos de revisión. Trabajos que plantean una revisión bibliográfica de un determinado ámbito de estudio relacionado con la temática que la publicación aborda. Pueden, adicionalmente, ocuparse de las ideas o aportes de los autores más relevantes, o pueden presentar una investigación respecto del "estado de la cuestión" de determinado tema.

d. Reportes de casos. Presentan los resultados y conclusiones de una investigación específica, con la finalidad de informar sobre los aspectos técnicos y metodológicos de la misma. Complementariamente, pueden incluir una revisión y comentario de la literatura sobre casos análogos.

e. Semblanzas. Bosquejos biográficos que destacan los aspectos más sobresalientes — siempre vinculados con la temática de la revista- del carácter, los estudios y la relevancia histórica de un personaje o institución, de los que busca reconocer sus logros y destacar el papel que jugaron en el desarrollo de la sociedad o de determinada área del saber.

f. Traducciones o reseñas bibliográficas. Textos breves en los que se ofrece una visión crítica y panorámica de una publicación, generalmente de reciente aparición.

g. Ponencias o comunicaciones a congresos.

\section{Normas generales para la presentación de los artículos de investigación}

1. Todos los artículos deberán ser originales e inéditos. Se presentarán impresos y en soporte magnético (CD), en formato A4 y a espacio y medio. Tendrán una extensión mínima de 20 páginas y una máxima de 40 páginas. El tipo de letra a usar será Times New Roman, en tamaño de 12 puntos. 
2. Luego del título de cada artículo, que deberá consignarse en castellano e inglés, se presentarán los nombres y apellidos del autor o autores, con una llamada $\left(^{*}\right)$ a nota de pie de página que contenga el nombre de la institución de trabajo del autor o autores, grados y correo electrónico de cada uno de ellos.

3. Cada artículo deberá presentar al inicio un resumen del contenido del mismo no mayor de 20 líneas, tanto en castellano como en inglés (abstract), además de palabras clave también en castellano e inglés (key words).

4. La primera línea de todos los párrafos del texto tendrá un sangrado de $8 \mathrm{~mm}$, y no se considerará espacio adicional entre párrafos.

5. Las citas textuales con menos de seis líneas irán incorporadas en el texto, entrecomilladas, en tanto que las citas con más de cinco líneas se consignarán en párrafo aparte, con un sangrado de $1 \mathrm{~cm}$ en ambos márgenes y un tamaño de letra un punto menor, sin comillas.

6. Las notas al pie de página podrán ser aclaratorias o referirse a citas textuales o a citas indirectas. Si la cita es textual, la nota a pie de página correspondiente deberá contener los siguientes datos:

a) Libros. Nombre y apellido del autor. Título en cursivas. Número de la edición (si se tiene). Lugar de edición: editorial, año, página o páginas donde aparece la cita. Ejemplo:

Herman Northrop Frye. Anatomy of Criticism: Four Essays. Princeton: Princeton University Press, 1957, p. 76.

b) Artículos de revistas. Nombre y apellido del autor. Título del artículo entre comillas. Nombre de la revista en cursivas, número, volumen (año), página o páginas de la revista en que aparece la cita. Ejemplo:

Rolena Adorno. "El sujeto colonial y la construcción de la alteridad". Revista de Crítica Literaria Latinoamericana, 28, vol. 5 (1988), p. 60.

c) Capítulos de libros. Nombre y apellido del autor. Título del artículo entre comillas. En Título del libro en cursivas, ed. Nombre y apellido del editor, número de la edición (si hubiere). Lugar de edición: editorial, año, páginas del libro en que aparece la cita. Ejemplo:

Walter Mignolo. "Cartas, crónicas y relaciones del descubrimiento y la conquista". En Historia de la literatura hispanoamericana, tomo I, Época colonial, ed. Luis Iñigo-Madrigal. Madrid: Ediciones Cátedra, 1982, p. 108.

d) Tesis. Nombre y apellido del autor. Título de la tesis en cursivas. Nombre del tipo de tesis. Institución, lugar, año, página o páginas de la tesis en que aparece la cita. Ejemplo:

O. Coronado. Intento suicida en el Hospital General San José del Callao entre los años 2006 y 2007. Tesis de Maestría. Universidad Peruana Cayetano Heredia, Lima, Perú, 2012, p. 74. 
e) Artículos de periódicos. Nombre y apellido del autor. Título del artículo entre comillas. Nombre del periódico en cursivas. Fecha, sección, página del periódico en que aparece la cita. Ejemplo:

José Ignacio Cabrujas. “Con real y medio”. Nacional. 16 nov., 1990, sección C, p. 7.

f) Documentos consultados en páginas electrónicas. Se consignarán los datos correspondientes al tipo de documento (libro, artículo de revista, capítulo de libro, tesis) y se agregará la fecha de recuperación y la dirección web. Ejemplo:

Rolena Adorno. "El sujeto colonial y la construcción de la alteridad". Revista de Crítica Literaria Latinoamericana, 28, vol. 5 (1988), p. 60. Recuperado el 12 de febrero de 2012 desde http:// www.monografias.com/trabajos13/integcielintegcie.shtml

7. En el caso de citas no textuales (en el que solo se expone la idea de un autor), se procederá como en el caso de las referencias al final del artículo (ver ítem 8), salvo por la identificación del autor, que será siempre por nombre y apellido.

8. Al final de cada artículo deberá consignarse, en orden alfabético por el apellido, un listado solo de las obras consultadas y mencionadas en el artículo, bajo el título de REFERENCIAS. En este caso, las fuentes se mencionan sin consignar los números de la página o de las páginas donde aparece la cita textual. Sin embargo, en el caso de los artículos de revistas y de los capítulos de libros sí deben ir indicados los números de las páginas donde aparecen tales artículos y capítulos, así:

a) Libros. Apellido, nombre del autor. Título en cursivas. Número de la edición (si se tiene). Lugar de edición: editorial, año. Ejemplo:

Frye, Herman Northrop. Anatomy of Criticism: Four Essays. Princeton: Princeton University Press, 1957.

b) Artículos de revistas. Apellido, nombre del autor. Título del artículo entre comillas. Nombre de la revista en cursivas, número, volumen (año), página o páginas de la revista en que aparece el artículo. Ejemplo:

Adorno, Rolena. "El sujeto colonial y la construcción de la alteridad". Revista de Crítica Literaria Latinoamericana, 28, vol. 5 (1988), p. 55-68.

c) Capítulos de libros. Apellido, nombre del autor. Título del artículo entre comillas. En Título del libro en cursivas, ed. Nombre y apellido del editor, número de la edición (si hubiere). Lugar de edición: editorial, año, páginas del libro en que aparece la cita. Ejemplo:

Mignolo, Walter. "Cartas, crónicas y relaciones del descubrimiento y la conquista". En Historia de la literatura hispanoamericana, tomo I, Época colonial, ed. Luis Iñigo-Madrigal. Madrid: Ediciones Cátedra, 1982, pp. 57-116. 
d) Tesis. Apellido, nombre del autor. Título de la tesis en cursivas. Nombre del tipo de tesis. Institución, lugar, año. Ejemplo:

Coronado, O. Intento suicida en el Hospital General San José del Callao entre los años 2006 y 2007. Tesis de Maestría. Universidad Peruana Cayetano Heredia, Lima, Perú, 2012.

e) Artículos de periódicos. Apellido, nombre del autor. Título del artículo entre comillas. Nombre del periódico en cursivas. Fecha, sección, página o páginas del periódico en que aparece el artículo. Ejemplo:

Cabrujas, José Ignacio. “Con real y medio”. Nacional. 16 nov., 1990, sección C, p. 7.

f) Documentos consultados en páginas electrónicas. Se consignarán los datos correspondientes al tipo de documento (libro, artículo de revista, capítulo de libro, tesis) y se agregará la fecha de recuperación y la dirección web. Ejemplo:

Adorno, Rolena. "El sujeto colonial y la construcción de la alteridad". Revista de Crítica Literaria Latinoamericana, 28, vol. 5 (1988), pp. 51-63. Recuperado el 12 de febrero de 2012 desde http://www.monografias.com/trabajos13/integcie/integcie.shtml 


\section{Suscripción a la revista Lex de la Facultad de Derecho y Ciencia Política-Edición Semestral}

Precio por suscripción anual 90,00 nuevos soles

Número suelto $\quad 50,00$ nuevos soles

El precio no incluye gastos de envío a nivel nacional e internacional.

Solicitar información a a_castillo26@hotmail.com o m_bayona@uap.edu.pe 